\title{
CANCER OF THE UTERINE CERVIX
}

\author{
By A. H. Charles, F.R.C.S., F.R.C.O.G. \\ Gynaecological Surgeon, St. George's Hospital; Surgeon, Samaritan Hospital for Women
}

It is impossible within the compass of a short article to review all aspects of this disease. It is proposed, therefore, to concentrate mainly on the diagnosis and treatment.

Cancer of the cervix occurs frequently in parous women between 40 and 70 years of age. Nulliparous women represent only 7 per cent. of the cases. The disease is relatively uncommon in women of the upper classes and in Jewish women of all classes. The comparative immunity enjoyed by Jewesses is probably racial and not due to freedom from contact with smegma, as cancer of the cervix is common in certain African tribes where circumcision is ritual. The most important factor in aetiology is pregnancy, either through trauma to the cervix or to the cellular activity which takes place during pregnancy. Trauma alone is not responsible, as shown by the rarity of cancer in cases of procidentia, though the cervix is constantly exposed to friction and may be ulcerated. It is the cervix that is exposed for a long time to the action of a continuous cervical discharge that is liable to develop cancer perhaps passing through precancerous stages before true invasive cancer appears.

\section{Symptomatology}

The symptom of greatest significance is bleeding, which may be irregular or a sudden profuse haemorrhage, or menorrhagia. Occasionally, it follows coitus. In only 2.9 per cent. of the series collected by the British Empire Cancer Campaign and reported by Harnett was post-coital bleeding the first symptom. A vaginal discharge was the first symptom in 20 per cent. of these cases. Pain is seldom the first symptom and indicates advanced disease.

\section{Pathology and Diagnosis}

The clinical varieties are: (1) ulcerative, (2) proliferative or cauliflower, (3) sclerosing, sometimes known as the 'worm-eaten' cervix, and (4) endocervical.

About 95 per cent. of these tumours are epidermoid cancers, the other 5 per cent. being adenocarcinomas. Histological grading is usually made in accordance with Broder's classification based on the degree of cell de-differentiation. Very few cervical cancers are Grade I (o to 25 per cent. of de-differentiated cells). Tumours with a large proportion of undifferentiated cells are the most malignant; they are also the most radiosensitive but are not equally radiocurable.

Spread of cervical cancer takes place by:

(I) Direct extension to the adjacent vaginal mucosa, upwards along the surface into the corpus, particularly in endocervical growths, or to the parametrium.

(2) Lymphatic spread, by the lymphatics of the parametrium outwards to the nodes lying in relation to the vessels on the pelvic wall. Lymphatic glands are situated along the external iliac vessels, being 8 to ro in number, arranged in three groups, one lateral, one medial and one in front of the vessels. The latter group is sometimes absent. Another important gland lies in the obturator fossa. Some smaller glands are distributed around the internal iliac artery and its $\rightleftharpoons$ branches. The so-called 'paracervical gland' is seldom if ever seen. Efferents from these groups of glands pass upwards to the common iliac and para-aortic nodes.

The stage to which a carcinoma has progressed is more important than histological grading when considering the probable outcome of treatment. Clinical staging is made in accordance with the League of Nations' classification. In Harnett's (1949) series, cases were staged as follows:

Stage $I$. The carcinoma is strictly confined to the cervix

Per

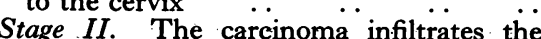
parametrium on one or both sides, but has not invaded the pelvic wall. Upper one-third of vagina infiltrated. Spread to corpus .. . . . . .

Stage III. The carcinomatous infiltration of the parametrium has invaded the pelvic wall on one or both sides. Lower one-third of vagina involved. Isolated metastases on pelvic wall .. ..

Stage IV. Carcinoma involves bladder as determined cystoscopically or a vesicovaginal fistula is present. Rectum involved. Distant metastases present ..

Not staged for lack of data

$\begin{array}{llll}\text {.. } & \ldots & 6 & 0.7\end{array}$

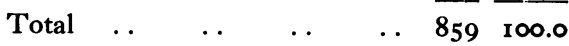

No. cent. $201 \quad 23.4$ 
In 1950, American gynaecologists put forward a revision of the League of Nations' classification which they termed the international classification. The only real change in this is to add Stage 0 to include carcinoma in situ and intra-epithelial carcinoma. It must be emphasized that staging is done from clinical data and cannot take into account lymph node infiltration. Some correction of the staging is possible in cases submitted to operation, but such correction would falsify comparison of the results of operation with the results of radiotherapy.

The diagnosis of the established case is generally obvious on digital and speculum examination. Improvement in the results of treatment must come mainly by earlier recognition of the disease and it is to this end that much recent research has been directed. However, for some time to come, the detection of cervical cancer in a curable stage will depend upon the prompt attention of patients and their doctors to symptoms. In Harnett's series 20 per cent. of the patients allowed from three to six months to elapse before consulting their doctors and over 25 per cent. allowed more than six months to go by before seeking advice. Some delay must be attributed to the doctor, but in Harnett's series, 80 per cent. of the patients were examined vaginally at once or within a month of the first consultation. Of those who consulted a doctor 80 per cent. were referred to a hospital at once. Howson and Montgomery (1949) in Philadelphia found that in the analysis of $I, 140$ cases, the average duration of delay attributable to the doctor was 7.4 months. In about half of the cases of delay, no local examination was made.

Doctors should make it a rule that if the patient declines a vaginal examination when symptoms point to the possibility of cancer being present, the doctor should decline to order any treatment. Palliatives will only prolong examination delay, while refusal to give any medicine may persuade the patient to submit to examination. Unfortunately, the symptoms may be insignificant until the growth has reached an advanced stage. If a reliable method can be found for diagnosis of cervical cancer at its onset or before clinical signs are present, then we shall have a real chance of reducing the mortality from this disease.

In 1928, Papanicolaou found cancer cells in the vaginal secretions of women with uterine cancer, but it was not until I94I that he co-operated with Traut to describe the vaginal-smear method of diagnosis of uterine carcinoma (Traut and Papanicolaou, I94I). Since then, many other clinicians have confirmed the vaginal smear as a valuable mcasure in the detection of early disease. There is a considerable variation in technique. Some collect the material for the smear from the miḍdle or top of the vagina, while others take it dire from the cervix or cervical canal, while Ayre (r949) and Novak (1947) obtain specimens by scrapin the cervix with a wooden spatula in the one case and a scalpel or sharp spoon in the other. Bis taking a direct scraping from the cervix, the ext foliated cells are obtained nearer their source and this surface biopsy is more accurate than a vagina重 smear.

Epidermoid cancer of the cervix arises from th $\overline{\mathrm{g}}$ squamo-columnar junction and, by scraping a round its margin, cancer cells are most likely to be picked up. Ayre found that when vaginal smears were taken from cervices which appeared suspicious of cancer and cancer cells were found to be present, subsequent biopsy confirmed cances in almost 100 per cent. of cases. However, whe the scrapings were taken from the squamos columnar margin of cervices that appeared normab and cancer cells were obtained, the subsequento biopsy often gave a negative result. The explanation lay in the difficulty of deciding from which area to take the biopsy. It is necessary to take a ring biopsy, thus obtaining all the tissue round the circumference of the squamo-columnar junctio and to submit this tissue to serial section. If small area is punched out of the circumference forto biopsy, it may only represent perhaps I/20thoof the tissue in which a carcinoma could be growing This work has proved that pre-clinical cancer mos lurk in a normal-looking cervix, and further that pre-clinical cancer is not necessarily pre-invasive or intra-epithelial or carcinoma in situ, but may b early invasive cancer. Pre-invasive cancer need not necessarily proceed ultimately to an invasive stage, but in some of the cases this undoubtedly takes place.

The interpretation of the material obtained by vaginal smear or cervical scraping is not easy an a long training is required before the cytologist findings become trustworthy. In America, cance?. diagnostic clinics have been set up and cytologicas examinations are made from the cervices of aA those who present themselves for examinationo Again in various gynaecological departments, the cervices of all patients attending the out-patien? clinic or admitted to the wards, are submitted to a smear examination. This entails a tremendous amount of laboratory work and it is estimated thaf it costs about 150 dollars to detect a case of pre invasive cancer. When a vaginal smear has proved positive, the presence of pre-clinical cancer muss be confirmed by a ring biopsy before any treatmen is instituted.

Attention has been drawn to the dangers ofo biopsy. Although it is not possible utterly to deny that biopsy could contribute to an accelerate\& spread of the disease, it is essential to obtain th 
reliable evidence that biopsy alone can afford before embarking on radical treatment. It is not justifiable to submit a patient to hysterectomy or radiotherapy on a smear diagnosis alone, as 'false positives 'are still not uncommon. Nevertheless, the vaginal smear or cervical scraping can help in cancer diagnosis and one has to consider how its use could be developed in this country. To make the method available to women in all the large centres of the British Isles and to persuade women to avail themselves of these facilities seems on contemplation to be an insuperable task in the present state of economy. It is questionable whether the incidence of uterine cancer is sufficiently high to warrant the enormous expenditure which would be involved in the setting up of such centres, when one considers the rival claim of clinics urgently needed to combat highly prevalent diseases, such as pulmonary tuberculosis.

\section{Pre-Cancerous Lesions of the Cervix}

Many pathologists believe that a condition is either benign or malignant and deny that there is a recognizable transitional stage through which a lesion passes before a true cancer develops. The cervix uteri is the site of chronic irritative lesions, as a result of child-bearing, perhaps more frequently than any other area of the body and, in addition, is exposed throughout reproductive life to hormonal activity. In addition, as mentioned previously, it is the site of considerable cellular activity and therefore might well be expected to exhibit pre-cancerous changes if such exist. On the other hand, the cervix so often shows marked erosion and hypertrophy and a readiness to bleed when touched and yet, when biopsy is performed, the histological picture is not in any way suggestive of cancer. Novak has emphasized that: - Some unknown constitutional predisposition or dyscrasia plays a fundamental role.' Cervical cancer may develop in a cervix that hitherto has shown no change from the normal, as witness the development of carcinoma in nulliparous women. However, the far greater frequency of cervical cancer in women who have had children, together with the frequency with which childbearing women have cervices showing chronic irritative lesions, must suggest most strongly the relationship between the trauma of pregnancy and the subsequent development of cancer.

\section{Epidermidization}

This is a condition which in the past has not infrequently been mistaken for a carcinoma and perhaps has improved the results of several centres. In this condition, squamous epithelium burrows beneath the columnar epithelium covering an erosion, lifting it up and sometimes destroying it.
When this process involves a gland, the squamous epithelium may ultimately completely replace the normal glandular epithelium, producing a collection of squamous cells that closely resemble carcinoma. This is most confusing when the squamous cells are found well below the surface. Here a squamous cell metaplasia may be the explanation. The characteristics of the cells and the absence of invasive tendency help to differentiate these areas from carcinoma.

\section{Leukoplakia}

This condition, well recognized as a precancerous lesion of the vulva, occurs infrequently on the cervix. Clinically, it may be observed as a white patch on the surface of the cervix. Strachan (1949) suggests that there is a considerable tendency for leukoplakia to progress to carcinoma. Hinselmann (1933) has used the term to cover a wide range of cellular changes which in their most advanced form (Rubric IV) are frankly carcinomatous. Novak and Meyer do not consider that all grades of leukoplakia are pre-cancerous, but Strachan suggests that leukoplakia may well be the connecting link between carcinoma and the chronicly damaged cervix. The author has subjected several cases in which leukoplakia was apparent on clinical examination to biopsy, with out histological appearances of pre-cancer being found and, up to the present, follow-up has not disclosed a case of cancer having developed: Perhaps this has been prevented by the deep cauterization which followed the biopsy. The histological appearance of leukoplakia in its early stages shows hyperkeratosis and increased activity in the cells of the basal layers which are close together. Hinselmann's interpretation of leukoplakia covers other probable pre-cancerous states that have been differently named by different observers.

Intra-epithelial Carcinoma: Carcinoma in situ: Pre-invasive Cancer

In this condition, the cells exhibit the characteristics of cancer cells without being invasive. The nuclei are hyperchromatic and mitotic figures are frequent; the normal differentiation of the basal cells into three layers is absent. Clumps of active epithelial cells are found lying in the stroma unconnected with the surface. One characteristic of cancer is missing-invasion. The basement membrane has not been penetrated. Carcinoma in situ may be regarded as histological but not clinical cancer (Fig. 2). TeLinde has shown that a long latent period may elapse before a preinvasive cancer becomes invasive, but he and Galvin (1944) have demonstrated that in the large majority, of cases this will happen unless the pre-

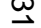




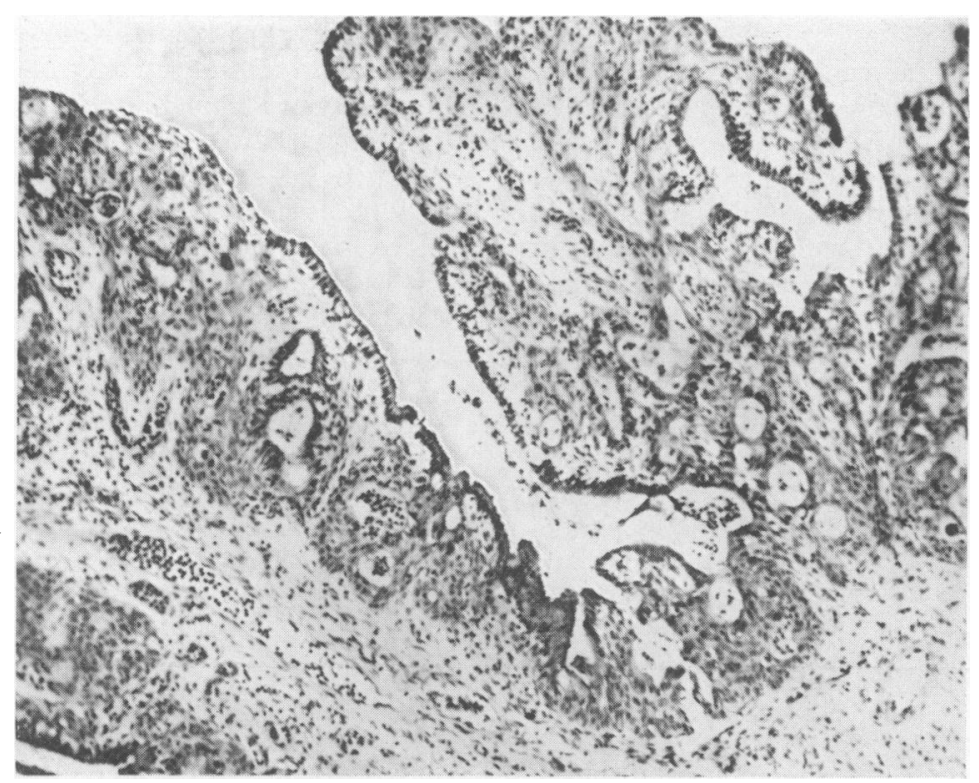

cancerous lesion is eradicated. Novak considers it a rare lesion and that repeated serial sections will generally reveal true invasive cancer somewhere in the cervix.

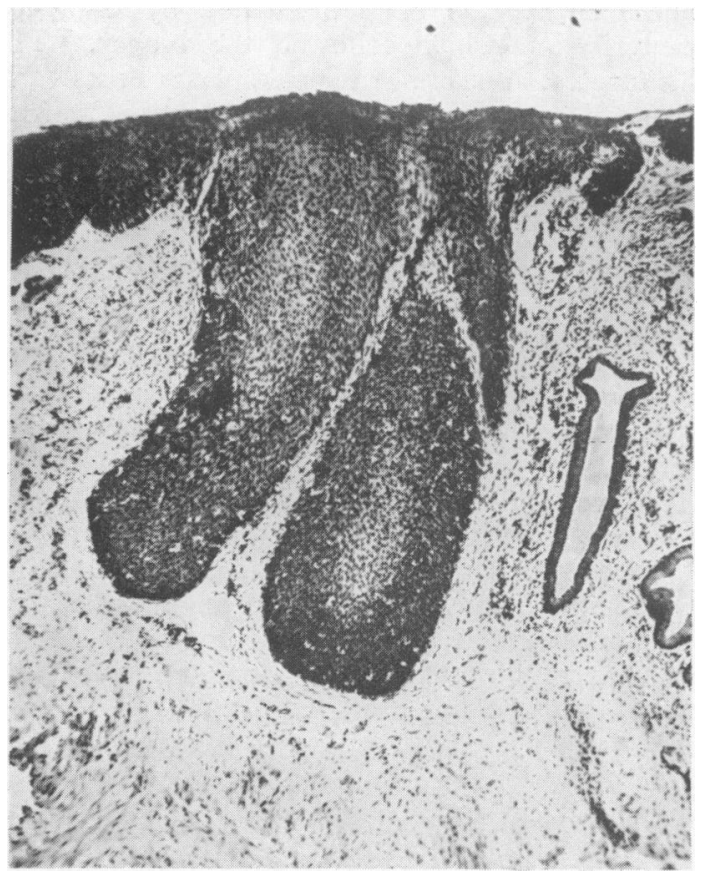

FIG. 2.-Carcinoma in situ (H. and E. $\times 40)$.

\section{Treatment}

This embraces prophylaxis, radiotherapy, spre $\overrightarrow{0}$ gery, combinations of radiotherapy and surgegy and palliative measures.

\section{Prophylaxis}

Much can be done to prevent a cervix becoming the site of cancer. We know that cervical cance? has been more common among the poorer classes $\overrightarrow{\overrightarrow{0}}$ It may be because these women have children more often than their more well-to-do sisters, bue the likely explanation is that they are less inclined. to make routine post-natal visits to their doctor and take less notice of vaginal discharges. In this way chronic irritative lesions of the cervix are allowed to remain present without treatment for years.

A good deal of preventive therapy can be in-o stituted without undue delay now that so many? women are delivered in hospital, and the erodedo cervix may be recognized at a post-natal visit and kept under observation. If it does not heal withino a few months, the cervix should be subjected ton a thorough cauterization. Thorough cauterization is seldom represented by superficial application of the nasal cautery in the out-patient department. If the cervix is the site of a chronic cervicitis of such a degree as to give rise to a constant vaginafes discharge, it is necessary to destroy the cervica $\vec{I}^{+}$ glands by deep cauterization under anaesthetic. The wearing of pessaries for a long time should苂 be abandoned. 
If hysterectomy is indicated for any condition. the operation should include removal of the cervix,

\section{Definitive Treatment: Radiotherapy}

For the past 30 years radiotherapy has held the field. For a proper understanding of the scope and the limitations of radiotherapy one must possess a simple appreciation of the properties involved. The radium atom emits alpha, beta and gamma rays. The gamma rays are those employed therapeutically, the others having no treatment value and in practice are screened off from the tissues. The intensity of irradiation falls off rapidly as the distance from the source increases. It obeys the law of inverse squares. In other words, the intensity of irradiation diminishes in proportion to the square of the distance from its source.

Obedience to this law represents one of the major difficulties in treatment of a tumour. The ideal would be to subject all parts of the tumour and its lymphatic field to an equal, cancericidal dose. In order to do this, it would be necessary to distribute the radium homogeneously throughout the area to be irradiated. This is never achieved and, in the case of cervical cancer, the best distribution of radium is far from the ideal. Attempts to distribute the radium by implantation of needles over a large area of the field have not been successful and today we rely mainly on intracavitary radiation, by which one can give a cancericidal dose to the central area but not to those peripheral areas which may harbour cancer cells. Moreover, in setting out to kill the cancer cells, one must have regard for the normal structures adjacent to the tumour, which may be irreparably damaged if an excessive dose is applied.

Practice has shown that it is necessary to give a dose a little short of the maximum which can be withstood by the normal tissues, and that the results of therapy will improve with increased dosage up to a certain level and then decline if this level is exceeded because high-dosage effects then play a detrimental part. The ureter, bladder and rectum may be damaged and general necrosis in the pelvis may follow if the dose is excessive.

For correlation of results and co-operation with physicists and radiotherapists, we must express our radium dosage in ' röntgens.' To speak of milligramme-hours merely implies that so much radium is placed in the vagina and uterus for so many hours. The uterine applicator is fairly constant in position, but the vaginal applicators vary in their distance from points $A$ and $B$ according to the size of the tumour, the cervix, the vagina or the applicator and, equally important, according to the constancy with which the applicatar remains in position. So many milligramme- hours in one case may represent an entirely different tumour dose to the same number of milligramme-hours in another case. The expression milligramme-hours ignores the vital factor of $\frac{\varrho}{c}$ distance.

The technique of applying intracavitory irradia- $\overrightarrow{\vec{D}}$ tion varies considerably, but in this country, until very recently, the Stockholm method using the well-known rectangular boxes was that most widely used. These boxes are satisfactory if carefully applied, far out in the vagina, and securely maintained in position, but they are liable to slip, because a rectangular box is not best suited to the cavity in which it is lodged.

Radiotherapists have defined two points as being convenient at which to calculate the tumour dose. Point $A$ is set $2 \mathrm{~cm}$. from the midline and $2 \mathrm{~cm}$. above the vaginal fornix; point $B$ is $5 \mathrm{~cm}$. from the midline and $2 \mathrm{~cm}$. above the vaginal fornix. Point $A$ roughly corresponds to where the uterine artery crosses the ureter and, therefore, represents a point where a vital normal structure lies. The dosage at point $A$ should be as high as possible without endangering the ureter. Somewhere in the region of 7,5 oor to 8,000 r is the usual dose employed, and this is cancericidal to most squamous-celled tumours. The efficacy of the treatment is limited because, from an intracavitar source, a tumour dose of 7,5 oor at point $A$ is onl about 2,000 r at point $B$, a dose which is not curative.

If the parametrium is involved as far out as the pelvic wall and glands are invaded, it is necessary to supplement the radium by external irradiation. Once again, the tumour dose from external irradiation is limited by the normal structures through which the $\mathrm{X}$-rays have to pass and it is not possible by external irradiation alone to expose the parametrium and the glands to a cancericidal dose without irreparable damage to the skin and other intervening structures. It is clear, therefore, that for radiation therapy there is a therapeutic limit that cannot embrace all tumours.

In the Manchester technique, a tandem in the uterus and two rubber ovoids in the vagina separated by spreaders of various sizes are used. The ovoids are of three sizes to fit vaginae of different dimensions and, by careful experiment and calculation, a unit system was devised where, by varying the number of units of radium in the ovoids according to their size, the same dose at point $A$ was obtained from the small ovoids containing three units, the medium containing four units or the large containing five units.

The uterine tubes are in three sizes, long, medium and short, the long containing five units, the medium three and the short two. It is desirable to use the longest tube and the largest ovoid 
which can be applied and to space the ovoids as widely as possible. The larger ovoid providing greater distance between the radium and the vaginal mucosa will lessen the dose received by the mucosa and thus allow a larger depth dose without damage. Tod worked out an optimum dose in the paracervical triangle from the results of treatment judged by survival and the effects of radium injury, and she showed that above a certain figure the results declined as high-dosage effects took their toll. Optimum dosages as given by her are (Tod, 1947):

\section{8,000 to 8,500 In ten days measured at point $A$ for radium alone. \\ 10,000 to 10,500r Combined dose at point $A$ for radium plus external $\mathrm{X}$-radiation over five to six weeks' treatment time.}

If the dose is increased in an attempt to deliver up to 6,000 at point $B$, high-dose effects on the normal tissues negative any benefit that in theory should be obtained from the higher dose at the pelvic wall. In practice, with the Manchester technique, using the longest intra-uterine tube and the largest applicators in wide vaginae, the dose at point $B$ is little more than 3 ,ooor and generally only about 2,5 oor. Under the most favourable conditions, a dose of 6,000 r could be obtained at a maximum of $4 \mathrm{~cm}$. from the midline. A study of the isodose curves plotted for intracavitary irradiations demonstrates the high dose delivered to the region of the cervix, base of bladder and rectovaginal septum and the rapidity with which it falls off at the periphery. Cantril (1950) has compared the paracervical and lateral parametrial tissue doses in the various techniques and found that in the Stockholm and Paris methods it is 1,000 to 2,000 r less than in the most favourable Manchester application, but he stresses that: "Whatever the technique used and however the dosage is assessed, it is not only dangerous but in most instances futile to force the dose in the more peripheral zones of the pelvis to a predetermined effectual dose.'

When external irradiation is added to the maximum intracavitary irradiation, it is necessary to shield the central area of the pelvis in order that it should not be overdosed.

$\mathrm{X}$-ray therapy is usually given by multiple high-voltage $\mathrm{X}$-ray beams, but super-voltage $\mathrm{X}$-ray treatment is being employed to a larger extent. There are technical advantages to be gained in the higher voltage range because the depth dose is more favourable and, probably what is more important, the bone absorption of irradiation is relatively less. However, it is doubtful whether super-voltage therapy will give an appreciable increase in the five-year survival rate.

While dosimetry acts as a useful guide to treat- $\frac{\widehat{\Phi}}{\mathbb{Q}}$ ment, it must not be followed slavishly in each $c$ individual case, for variance in the anatomy and pathology and in the biological response will often $\stackrel{\oplus}{\stackrel{P}{+}}$ require dose modification.

At the Samaritan Hospital the unit employed $\frac{\overline{0}}{\bar{c}}$ is $5 \mathrm{mgm}$. and the applications are made at weekly $\vec{\nabla}$ intervals on three occasions. The ovoids are held $\cong$ in place by gauze packing which, despite all efforts 5 to find a better substitute, still remains the most $\overrightarrow{0}$ efficient medium for widely varying tumours and vaginae. The application is made with the $\vec{\omega}$ patient in the knee-chest position thereby making use of the full distention of the vagina by the $\frac{0}{3}$ atmospheric pressure. In this position, it is com- $\frac{3}{i}$. paratively easy to place the ovoids in the desired 0 situation and to insert the packing in such a way that the rectum is protected and the ovoids are $\infty$ fixed in position (see Figs. 4, 5 and 6). The dose N which has been employed is 7,500 to 8 ,ooor at 0 point $A$, but this is reduced to 7,000 r in older $\overrightarrow{-}$ women. The position of the radium is checked $\vec{D}$ by $\mathrm{X}$-ray after each application. The radium is removed and reapplied if there is any gross mal- $\overrightarrow{.}$ position. The dosage rate per hour of the variogs of combinations has been calculated by the physicie. Calculation is not necessary for each individu case, provided the X-ray shows the normal patte而会 and distances.

Individual curves are plotted if the size and $\stackrel{0}{\Phi}$ shape of the tumour does not allow the applicators $\cong$ to lie symmetrically. At subsequent applications, $\overrightarrow{\overrightarrow{0}}$ alterations in quantity of radium and time are 3 made in order to submit all the tumour area to an adequate dose. Supplementary $\mathrm{X}$-radiation is used for tumours in late Stage II or Stage III in an attempt to boost up the dose at point $B$, though the sum of irradiation from radium and X-rays 3 unfortunately falls short of what may be required. By splitting the radium application into three $\frac{3}{3}$ doses, it was found that there were less complications such as pyrexia, sickness, proctitis, cystitis and the like than when the same dose was $\frac{7}{0}$ obtained by two longer applications.

When the cervical tumour is large, it may o render the application of radium difficult and, in $N$ cases of exfoliative growth almost filling the upper N reaches of the vagina, it is advantageous to treat 0 the patient by X-rays first, and this generally brings about a marked reduction in the size of the tumour. The dose employed at the Samaritan is $\stackrel{\oplus}{+}$ usually about 2,500 r to the centre of the pelvis 0 delivered over 14 days. The subsequent intra- $\bar{O}$ cavitary dose must be reduced so that the optimum $\stackrel{\mathbb{\Phi}}{\Omega}$ is not exceeded in the central region. 


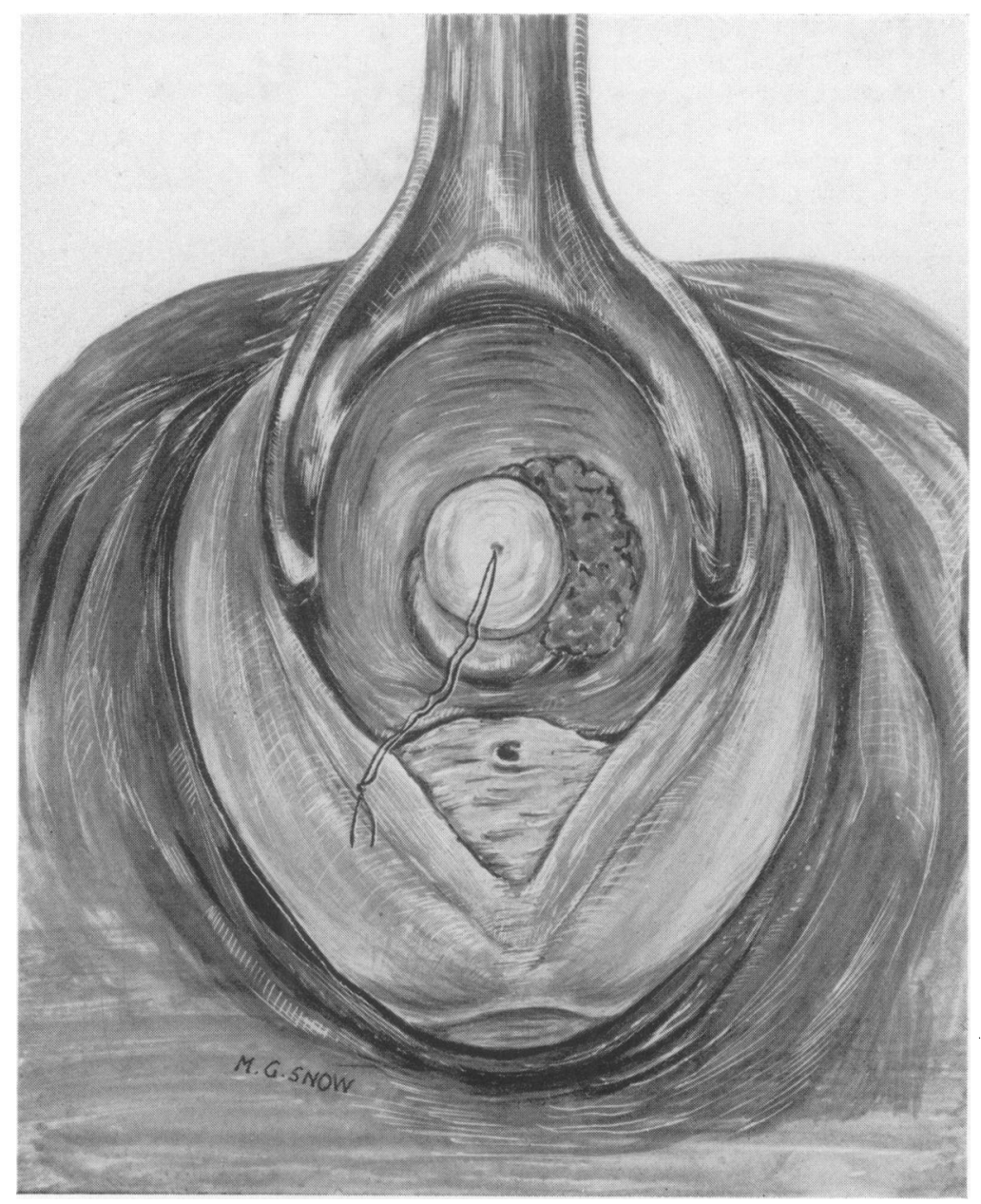

Fig. 4.-Patient in knee-chest position; uterine tandem inserted.

\section{Complications of Radiotherapy}

Infection is the complication which most frequently gives difficulty. When the growth is infected, much benefit may be obtained by preliminary external X-ray treatment combined with the use of sulphonamides, antibiotics, vaginal douching and treatment of anaemia. If pyosalpinges or tubo-ovarian abscesses are present, they are best dealt with surgically before radium treatment is given. The only fatality from radiation therapy at the Samaritan Hospital in the last five years occurred in a case where chronic tuboovarian infective masses were confused with parametrial spread and infection flared up after the radium was applied. The tubes and ovaries were later removed but, after a long illness, the patient succumbed.
Pyometra in the absence of pyrexia seldom gives rise to trouble unless the uterus is perforated during the insertion of the radium. Preliminary drainage is advisable if there is pyrexia.

Vesical reaction as shown by urgency and frequency, does not often interfere with treatment but care should be taken in subsequent applications to pack the radium well away from the bladder base.

Proctitis is usually of a mild and transitory nature characterized by diarrhoea and tenesmus, and clears up spontaneously. It is more likely to occur when the uterus is retroverted. Use of the knee-chest position for applying radium helps to obviate the risk of proctitis. When the reaction is more severe, benefit may be obtained from saline rectal washouts and liquid paraffin by mouth. 


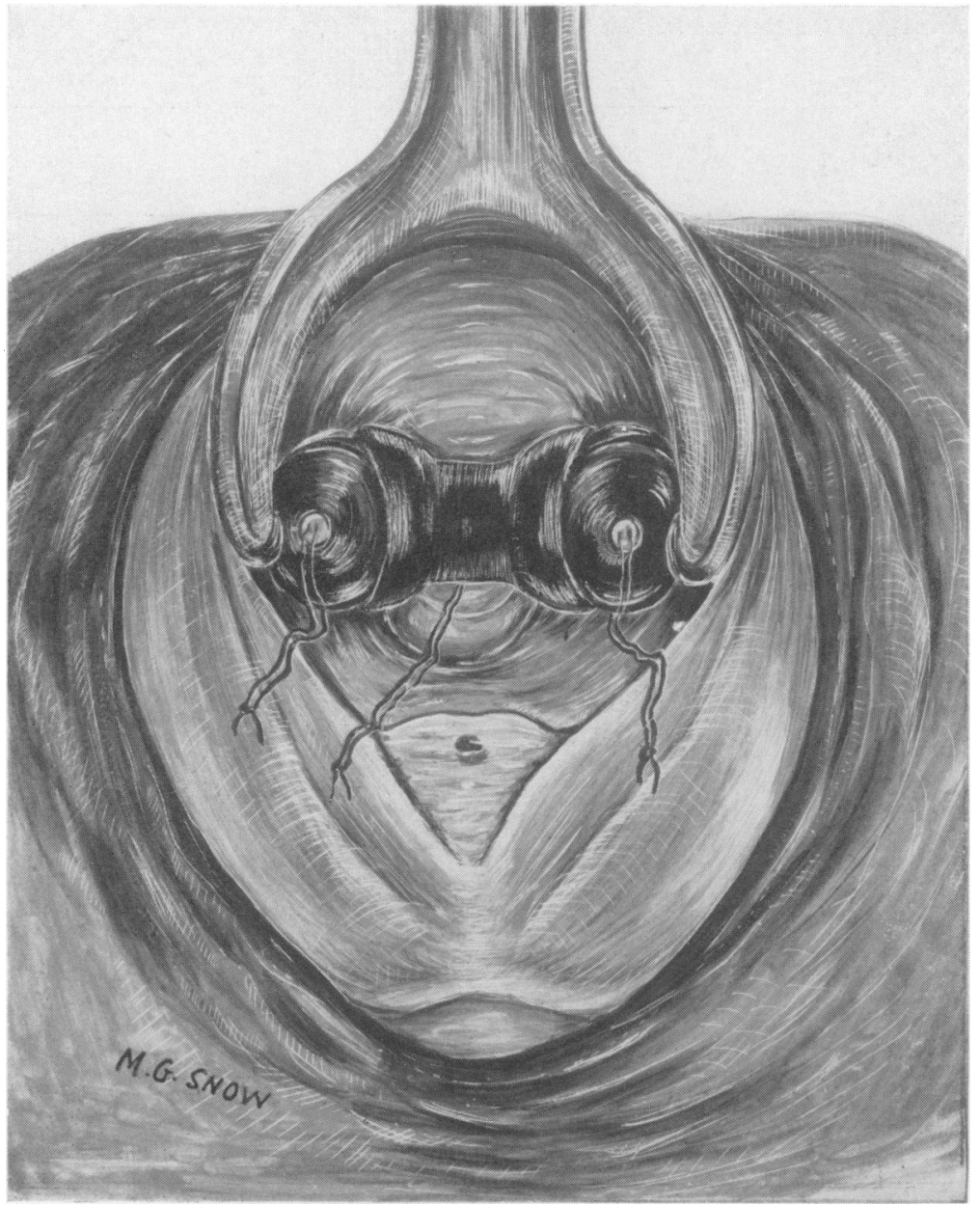

FIG. 5.-Patient in knee-chest position; large ovoids and spacer inserted.

Radiation sickness is very seldom severe when treatment is confined to the pelvis. Pyridoxine, ro mgm. three times a day, is useful for this complaint.

\section{Late Complications}

These are lesions of late radium necrosis which may affect the cervix, bladder, parametrium or rectum. Radium necrosis of the cervix may leave an ulcer which is difficult to distinguish from a recurrence and time alone will give the answer. The late effects on the urinary apparatus may be serious. Bladder necrosis may occur with normal dosage carefully applied or when the applicators have pressed too tightly or when the growth has invaded the bladder. In the latter instance, a vesico-vaginal fistula will probably result. In lesser cases, an ulcer is produced in the base of the bladder giving rise to frequency and pain, with moderate pyrexia. Chemotherapy and bladder lavage will generally produce a cure in time, buts a few cases may require ureteric transplantation.

Ureteral stenosis may develop late from then effects of radium necrosis and cause the death of a patient otherwise cured. In the majority of cases, however, ureteric obstruction is the resultiv of the growth and not the treatment. Where the ureters are seriously obstructed, transplantation iso indicated, if the expectation of life warrants ano operation.

Late rectal reaction may occur months after treatment. There will have been proctitis at the $e_{\mathbb{8}}^{\circ}$ time of treatment. The late reaction is accom- $\mathrm{Q}$ panied by tenesmus and painful defaecation with 


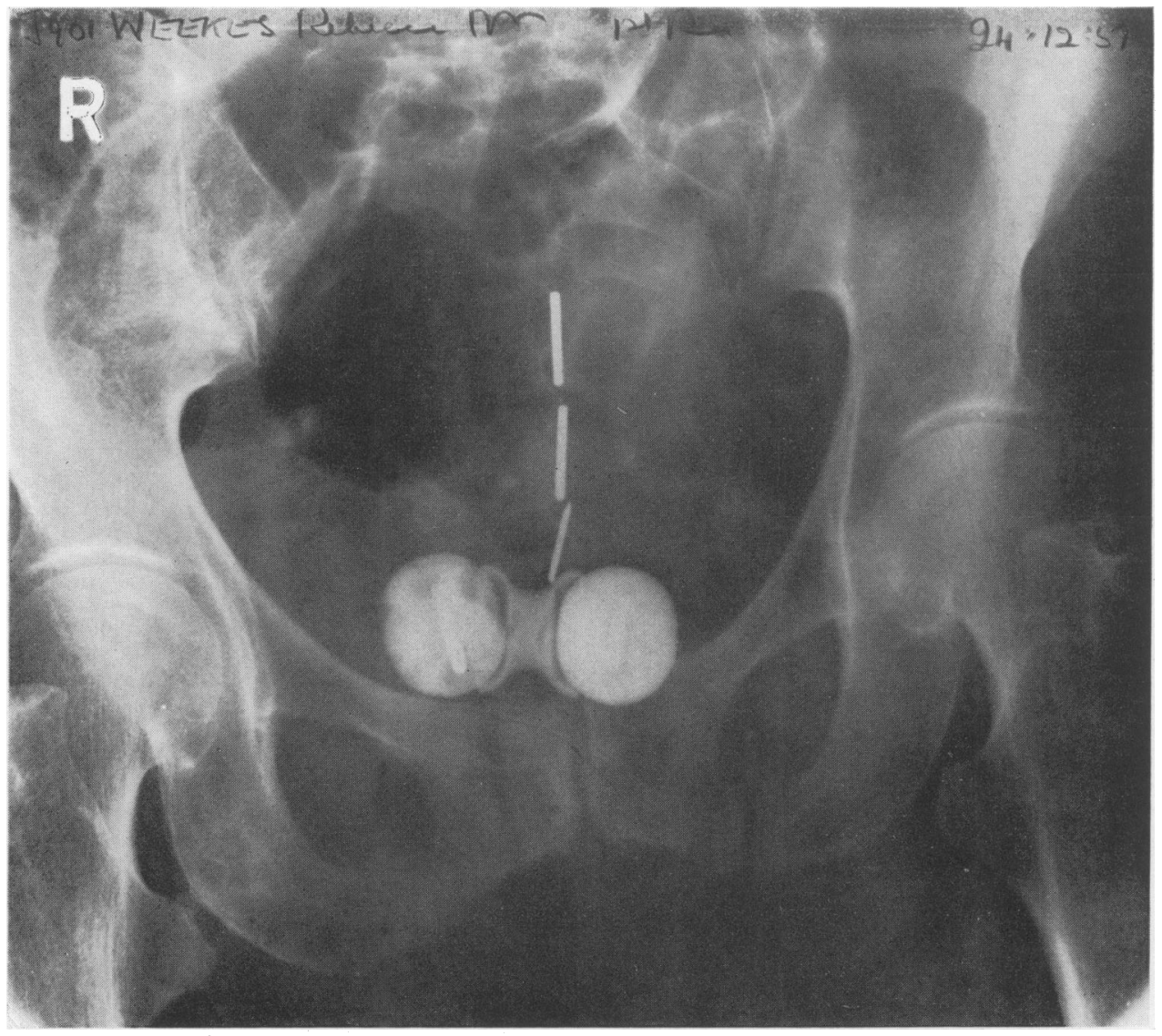

Fig. 6.-X-ray of pelvis showing long intra-uterine tandem containing five units and medium ovoids containing four units each, separated by spacer.

the passage of blood and mucus. An ulcerated area may be found on the anterior rectal wall with surrounding induration, and the lesion has been called pseudo-carcinoma.

Treatment is conservative. Sometimes a late reaction may heal with much fibrosis resulting in rectal stenosis or the tissues may necrose to produce a recto-vaginal fistula.

The mortality of radiation treatment is between $I$ and 2 per cent.

\section{Results of Radiotherapy}

In order to determine the value of radiotherapy it is essential to study the sum of results from a number of centres at which there is no selection of cases. Pre-cancerous conditions must be excluded and patients who died of intercurrent disease included among those who died of cancer. The sixth volume of statements of results (Annual
Report, I95 I) obtained in 1943 and previous years from 37 centres in I I countries reviewed by a committee consisting of Heyman, Donaldson and Meigs provides the latest bulk figures which fulfil the above conditions:

4I,046 patients were treated. Of these,

3 I.8 per cent. were alive and well after five years;

I.5 per cent. were alive with cancer;

64.8 per cent. had died of cancer or intercurrent disease;

I per cent. had been lost.

Five-year survival rates for stages are:

6I per cent. for Stage I.

40 per cent. for Stage II.

22 per cent. for Stage III.

6.5 per cent. for Stage IV.

Certain clinics produce figures that are far 


\begin{tabular}{|c|c|c|c|c|c|c|c|c|c|c|c|}
\hline \multirow[b]{2}{*}{ Institution } & \multirow[b]{2}{*}{ Years } & \multirow{2}{*}{$\begin{array}{l}\text { Total } \\
\text { No. }\end{array}$} & \multicolumn{2}{|c|}{ Stage I } & \multicolumn{2}{|c|}{ Stage II } & \multicolumn{2}{|c|}{ Stage III } & \multicolumn{2}{|c|}{ Stage IV } & \multirow{2}{*}{$\begin{array}{c}\text { Relative } \\
\text { curabilit } \\
\%\end{array}$} \\
\hline & & & No. & $\begin{array}{c}\% \\
\text { Well }\end{array}$ & No. & $\begin{array}{c}\% \\
\text { Well }\end{array}$ & No. & $\begin{array}{c}\% \\
\text { Well }\end{array}$ & No. & $\begin{array}{c}\% \\
\text { Well }\end{array}$ & \\
\hline $\begin{array}{l}\text { Allgemeines Kranken- } \\
\text { haus St. Georg, Ham- } \\
\text { burg .. }\end{array}$ & $1935-39$ & 607 & 83 & 63.8 & 195 & $5^{\mathrm{I}} \cdot 3$ & 291 & $33 \cdot 3$ & 38 & $5 \cdot 3$ & 41.6 \\
\hline \begin{tabular}{cccc} 
Institut & du & \multicolumn{2}{c}{ Radium, } \\
Paris & & $\ldots$ & $\ldots$
\end{tabular} & 1919-4I & 2199 & 298 & 63.4 & 942 & 42.8 & 739 & 27.6 & 220 & 9.1 & 37.1 \\
\hline $\begin{array}{ll}\text { Marie Curie } & \text { Hospital, } \\
\text { London } & \ldots\end{array}$ & $1925-4 I$ & 1514 & 118 & 77.1 & 420 & 56.4 & 769 & 28.2 & 207 & 7.7 & 37.1 \\
\hline $\begin{array}{ccc}\text { Radium Centre, Copen- } \\
\text { hagen } & \ldots & \ldots\end{array}$ & $1938-39$ & 468 & 49 & $6 z .3$ & 224 & 51.8 & 142 & 35.9 & 53 & 15.1 & 44.4 \\
\hline $\begin{array}{c}\text { Tumor Institute, Swed- } \\
\text { ish Hospital, Seattle. }\end{array}$ & $1935-44$ & 249 & 34 & 88.2 & 87 & 51.7 & 104 & 32.6 & 24 & 8 & 44.1 \\
\hline
\end{tabular}

better than the average. The following gives a selection of the best:

Improvement has been considerable over the past quarter of a century. At the Radiumhemmet, Stockholm, from 1914 to 1933, the absolute fiveyear cure rate was 22.3 per cent., while for 1934 to 1943 it was 38 per cent. Heyman (1947) has emphasized that this is largely brought about by individualization of the treatment and states that some modification of the standard technique was advisable in 45 per cent. of the patients treated, generally on account of infection. He draws attention to the extensive use of electrofulguration for local recurrences. Thoren (1945) reports that of 38 patients with proved recurrence i I were alive more than four years under such treatment.

The place of supplementary external X-radiation is illustrated by some recent figures of results at the Holt Radium Institute, Manchester. Xradiation reduced the relative five-year survival rate in Stages I and II from 56 per cent. to 46 per cent. but improved the results in Stages III and IV cases from 20 per cent. to 27 per cent.

\section{Failure of Radiation Therapy}

Earlier it has been emphasized that staging of the disease is a clinical appreciation of the extent of the growth and cases placed in Stage I may have undetected lymph node involvement. This will explain a proportion of the 20 per cent. failure in the treatment of so-called Stage I cases. Lacassagne (1941), Baud (1948) and Cantril (1950) have all drawn attention to the fact that failure in the treatment of early cases very seldom arises because of failure to control the disease in the cervix itself. Most of the failures are attributable to unsuspected advancement of the disease to the nodes or outside the pelvis, a few to inadequacy of the dose and a few to radio-resistant tumours.

\section{Surgery}

Wertheim (1905) began his operation in Wegan his operation in 1899 and he had 30 deaths in the first 100 operations. In 1905 , he read a paper at Leicester claiming a 40 per cent. five-year cure. It was this paper thatstimulated Bonney to take up the operation and to extend it. Bonney introduced the routine removal of the pelvic lymph glands and extendedte his operation to remove as much of the vagina os su possible. Bonney's operability rate was estimated at 63 per cent. He operated on every case In? which he thought there was a chance of a cure His operability rate among private patients wasn 80 per cent.

In I94I, he published the results of 500 operations on a five-year basis and 4I5 on a ten-yearo basis (Bonney, I94I). The five-year survival rate was 40 per cent. and the ten-year survival rate 3I per cent. The operative death rate was I4 per cent. Of every 100 unselected cases seen, his absolute survival on a five-year basis was 26 per:cent. and on a ten-year basis $2 \mathrm{I}$ per cent. His operative mortality rate fell to I I per cent. in the last 200 cases.

With the advance of radiotherapy, radical sur-o gery fell into disrepute largely because of the high? initial mortality, but once again gynaecologists areo looking towards surgery to achieve further advances in the treatment of cervical cancer? Major surgery has been made so much safer by the great improvement in anaesthetics, the dis covery of sulphonamides and antibiotics, and un- limited supplies of blood. Operative mortality today should not exceed 2 per cent., except for the extended operation occasionally employed fore? Stage IV growths.

The renewed employment of surgery need noto lead to a conflict with the radiotherapists for, in great measure, the methods of treatment can $\frac{\vec{\alpha}}{\alpha}$ 
progress side by side each assisting the other. In the early cases, however, there is bound to be competition, for the case that does best with surgery is the one that the radiotherapist is most likely to cure. The ideal case for surgical attack is a Stage I or early Stage II growth occurring in a woman otherwise healthy, of moderate age and figure. We have seen that even in Stage I cases there is at least a $I_{5}$ to 20 per cent. failure from irradiation. It remains to be seen whether under modern conditions those failures can be eliminated by surgery. The reasons advanced that this may be so are: (I) If the cervix is removed, there can be no recurrence there (against this argument is the very small incidence of local recurrence after adequate irradiation); (2) that certain tumours of the cervix are radio-resistant; and (3) the most important, that patients with clinical Stage I cases may have involvement of the pelvic lymph nodes which many believe cannot be cured by irradiation.

Meigs (I95I) reports the five-year results of 75 patients treated by radical hysterectomy with dissection of the lymph nodes (Stages I and II). Fourteen had positive lymph nodes and four of these are alive at the end of five years. Twentyseven patients had radiotherapy in addition to surgery and of these 19 survived. Of the remaining 48 who had surgery alone, 39 survived (88.3 per cent.) and of ${ }_{5} I$ patients with Stage I cancer 44 (86.3 per cent.) were alive after five years, including three in whom the lymph nodes were invaded. In 1949, he stated that 100 successive patients at the Massachussetts General Hospital, Pondville Hospital and Palmer Memorial Hospital had been operated upon without a death and 200 with only one death. It can be seen that among selected patients with an early-stage cancer operated upon by Meigs, the cure rate is higher than that obtained by radiotherapy, but for a true comparison we ought to know how many similar patients were rejected for operation on grounds other than the stage of the growth.

With regard to radio-resistant cases, Heyman (1949) is sceptical of their existence and, until the results of operation upon so-called radio-resistant cases have been collected, entertains doubt whether this type of case is not only resistant to irradiation but to any form of treatment because of the high degree of malignancy.

A section of a colloid cervical carcinoma is shown in Fig. 3. This tumour showed no reaction at all to two applications of radium $(5,000 \mathrm{r})$ and was then submitted to radical hysterectomy. The glands were invaded on both sides and the patient only survived the operation by some eighteen months. A great deal of work has been done by Warren, et al. (I939) and by Glucksman and Spear

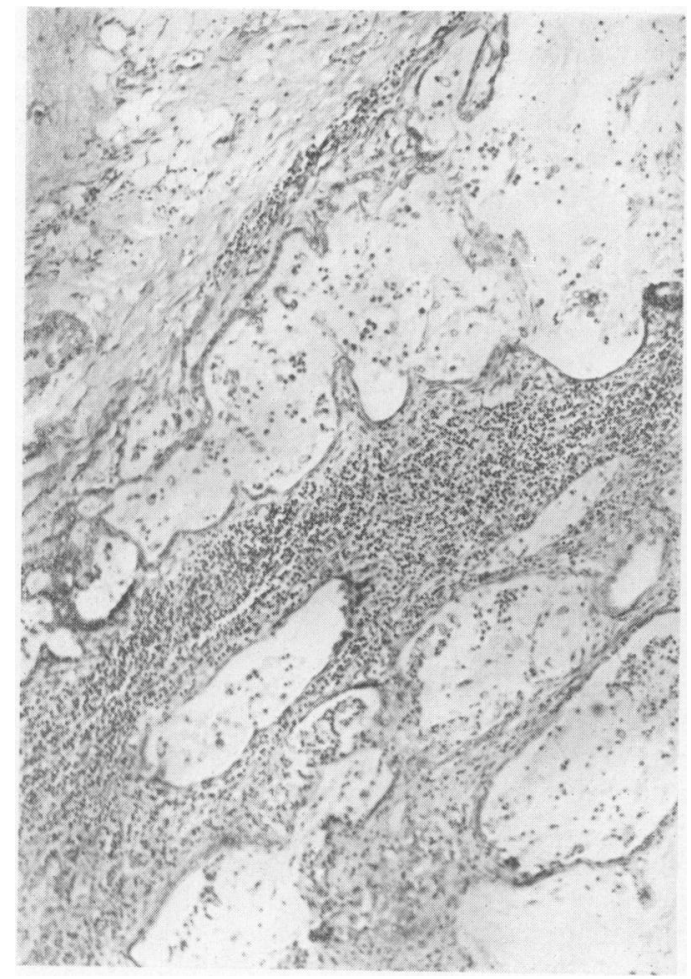

FIg. 3.-Colloid carcinoma of cervix (H. and E. $\times$ 30). ํํㄱ

(1945) on the effects of radiation by studying the early histological changes produced in biopsies taken during and after treatment.

Glucksman (1949) investigated the relation of tumour type to expectation of cure. Three series of patients were considered, comprising (I) those treated by a modified Stockholm method, not in all cases complete, (2) those fully treated by a Stockholm method and (3) those fully treated by a Paris method. In each series, the analysis was significant. Differentiated epitheliomas all gave better results than the anaplastic epitheliomas, which is contrary to the statements of some authors who contend that a higher proportion of anaplastic than of differentiated tumours of the cervix are radiocurable.

It is well known that differentiated tumours spread less rapidly and less extensively than undifferentiated tumours and offer a far better chance of cure by surgery. The same is true for radiotherapy. Anaplastic tumours often exhibit a dramatic response to radiation by rapid diminution in size, but their radiocurability rate is statistically lower than differentiated tumours of the same stage of advancement. 
In Glucksman's series, on a five-year basis, the differentiated carcinomas showed $19 \pm 2.9$ per cent. better results for the whole group of tumours and a significant advantage in each clinical stage. $\mathrm{He}$ sought to find whether the histological changes brought about by radiation would prove a reliable guide to radiocurability for any given tumour.

Clinical assessment is not good enough. The histological method of assessment is based on the fact that biopsies taken from the growing edge of the tumour include many young foci which are representative of the tumour as a whole, and which demonstrate early changes under the influence of radiation that are of prognostic value.

Successful radiotherapy converts viable cells into non-viable cells.

The effect of radiation on the cells of a tumour is both direct and indirect. The indirect effect is produced by its action on the blood vessels and stroma. Both influence cell population of active foci. Multiplication of resting cells may be inhibited or differentiation induced so producing nonviability. Cells undergoing mitosis may be killed. Glucksman emphasizes that the most important feature of radiocurable tumours is their ability to respond to radiation by increased differentiation and on the contrary, it is the persistence of unaltered foci that denotes resistance to radiation. The work is difficult and requires great experience to select the right material for biopsy, to prepare it and to interpret it. The cytological changes vary with the dose and the time between radiation and biopsy. Glucksman states that the cell count in comparable young foci is the most reliable method, though this is often unnecessary in radio-resistant cases showing no response.

From the cell count the response to radiation is put in three grades: (I) favourable; when all resting and mitotic cells are replaced by differentiating and degenerating cells, (2) partial when there is some change from viable to non-viable cells, and (3) unfavourable when only minor changes are found. Glucksman claims that the five-year follow-up of the clinical results in patients for whom a definite histological prognosis was given early in treatment has provided agreement in 97 per cent. The therapeutic value of histological prognosis will lie in diverting to surgery wherever feasible patients for whom radiotherapy offers no hope of cure. In many such cases, the lymph glands will be invaded and surgery prove unsuccessful. But since it offers the only hope, operation should be attempted and a few will survive.

Turning to the apparently early case with gland invasion, it is unlikely that any of such cases survived five years when treated by irradiation. With gland-involved cases, Bonney had a 22 per cent. five-year cure rate and 16-1 8 per cent. ten $\frac{0}{0}$ year cure rate. The argument for operating on the early cases is therefore clear. If the mortality and morbidity can be kept low, as it can nowadays and really thorough surgery carried out, it should. be possible to do appreciably better by surgerys than by radium.

\section{Combination of Surgery and Radiotherapy}

Most operators today employ either pre-operative or post-operative radiotherapy or both. Pre operative radium treatment is widely used and information has not yet crystallized as to the idea $\vec{p}$ pre-operative dose or as to the interval which $\vec{\omega}$ should elapse between the radium treatment and the operation. However, the tendency is towards employment of a dose two-thirds of that used if surgery is not contemplated. This would be of the order of 5 to $5,500 \mathrm{r}$. Six weeks has been $\omega_{\omega}^{\infty}$ suggested as the best time to allow between $\vec{\infty}_{\infty}$ irradiation and operation because this intervan allows the reaction to radium to subside so that the tissues are less oedematous and bleeding less? troublesome. Two to three weeks after irradiationmay be the least favourable as infection is more likely then.

Before operation, the blood must be examingd $\frac{1}{6}$ to determine the cell count and haemoglobin legen and where necessary a pre-operative transfusionsis given. The urine must be examined for presence of infection and any present eradicated Cystoscopy is performed to establish as far as possible freedom of the bladder from growth. If bullous oedema is present, this indicates involvement. The mucosa of the bladder is raised up ino을 an irregular fashion. Areas may bleed when touched. Red discoloration is a bad sign. Some times, the growth may obviously have penetrated the mucosa. While bladder involvement does not? absolutely preclude a surgical attack as will be dis cussed later, it rules out the ordinary Wertheim procedure.

Further pre-treatment investigation should include estimation of the blood urea, urea clearance test and an intravenous pyelogram. Before operation is commenced, a slow intravenous saline dripo is established which can be changed to a blood drip as necessary. The anaesthetic can be pento- $N$ thal, gas and oxygen, curare sequence or spinals The operation is carried out through a longs median incision or in the obese through a wide $\sigma$ transverse muscle-cutting incision. The operation includes a thorough dissection of the glands frome the common iliac vessels to the obturator foramen, the dissection of the ureter without stripping $i t_{0}$ entirely of its surrounding areolar tissue in ordero to preserve its blood supply, removal of the para-两 metrial tissues right out to the pelvic wall,,$\frac{\rho}{\mathbb{D}}$ 
removal of the pelvic peritoneum down to the bottom of the pouch of Douglas and removal of a cuff of vagina well beyond the lowest extent of the growth.

Where the cervical tumour is large, or where the growth has spread down the vagina to a considerable extent, it is an advantage to precede the abdominal operation by a vaginal stage such as that described by Brunschwig (I95I). With the patient in the lithotomy position, a Schuchardt incision is made deeply on the left side and carried upwards in the vagina one third of the way to the cervix. A circular incision through the entire thickness of the vagina is then made. Bladder and rectum are dissected from this cuff which is closed over a gauze pad. The rectum may then be separated from the posterior vaginal wall until the peritoneum of the pouch of Douglas is identified and incised. This will facilitate the subsequent freeing of the closed vaginal cuff from above. Alternatively, in the same type of case, Howkins' (I95I) synchronous combined abdominovaginal hysterectomy may be employed in which two teams work together, one from above and one from below. The whole of the vagina may be removed by this method without increasing the operating time to any great extent.

Post-operatively, most difficulty is likely to arise from bladder paresis, since the sympathetic supply to the bladder is necessarily injured in the operation. Continuous bladder drainage with an indwelling catheter is continued for a week and, after its removal, regular catheterization for residual urine must be continued until this has been reduced to $2 \mathrm{oz}$. Normal bladder function is generally restored, but this may sometimes be delayed for months.

The radical vaginal hysterectomy of Shauta is seldom employed in this country. Complete gland dissection is impossible through a vaginal approach.

Schlink (1950) of Sydney has employed a combined treatment of radium and Wertheim's hysterectomy since 1930. From 1930 to 1944, inclusive, 532 patients were seen and examined with a view to treatment and $5 \mathrm{II}$ treated. The absolute survival rate for all patients seen was 32 per cent. five years and 28.3 per cent. ten years, and for all patients treated the survival rate was 33.5 per cent. five years and 29.3 per cent. ten years. Of the 532 patients, 246 were treated by radium plus surgery and 253 by radium alone. In 33 , the treatment was nil or incomplete. Schlink further analyses his results excluding Stage IV cases, stating that those clinics which claim five-year cures for this stage must have mis-grouped them clinically. With the exclusion of Stage IV cases, very creditable figures emerge, as follows:

\begin{tabular}{lll|c|c}
\hline \multicolumn{1}{c|}{ Treatment } & & \multicolumn{2}{|c}{$\begin{array}{c}\text { Percentage } \\
\text { results }\end{array}$} \\
\cline { 3 - 4 } & & & $\begin{array}{c}\text { Five } \\
\text { years }\end{array}$ & $\begin{array}{c}\text { Ten } \\
\text { years }\end{array}$ \\
\hline A. Radium plus surgery & $\ldots$ & $\ldots$ & 54 & $5 \mathrm{I}$ \\
$B$. Radiotherapy alone & $\ldots$ & $\ldots$ & 18 & 13 \\
$C$. Average of $A$ and $B$ & $\ldots$ & $\ldots$ & 40 & 35 \\
\hline
\end{tabular}

If the 13 deaths in the five-year series and the 8 deaths in the ten-year series due to intercurrent disease were excluded the survival rates would be about 5 per cent. better than the above figures.

\section{Combined Radiotherapy and Iliac \\ Lymph-Adenectomy}

This method is based on the assumption that radiotherapy can take care of the primary growth while surgery clears the lymphatic field. It is thus comparable with interstitial irradiation for epithelioma of the tongue combined with block dissection of the glands of the neck. Taussig (1943) adopted a transperitoneal approach for the lymph node dissection. In 1943, he reported 175 operations of this type and produced fiveyear results better by approximately ro per cent. than the results obtained in a group of cases of similar extent in which comparable radiation had been given but the glands not dissected.

The glandular field of the cervix can be dissected through an extraperitoneal approach, which has the advantage of less disturbance to the patient and it can be done one side at a time in patients who are not too fit. Retroperitoneal lymph node dissection for cervical cancer was introduced by Nathanson. The author has employed it some six to ten weeks after irradiation for cases in Stage II or early Stage III where it was considered that radiotherapy had controlled the local growth as judged by clinical signs and post-radiation biopsies. It is especially suitable for cases who are not good risks for the extended Wertheim operation by reason of other disease or obesity. It would appear to offer a greater chance of cure for the plump woman with a wide pelvis suffering from cancer that has spread beyond the cervix. Such a case presents a problem in which radiotherapy alone has little chance of success if the lymph nodes are invaded, for they will be lying a long way from the centre of the pelvis and denied the full effects of supplementary external $\mathrm{X}$-radiation by intervening fat and bone.

The incision is made along the line of the inguinal canal from the pubis to a point about 2 in. above the anterior superior iliac spine. External oblique, internal oblique and transversalis muscles are divided in the line of the incision until the peritoneum is exposed. The inferior epigastric vessels are divided and ligatured. The peri- 
toneum is then pushed medially together with the round ligament, which may be divided if necessary. The ureter is found adherent to the posterior surface of the peritoneum and is displaced medially. A thorough dissection of the glands is carried out from about the middle of the common iliac artery or higher if indicated. The glands, fat and aerolar tissue covering the common iliac, external and internal iliac vessels is cleared completely, as is the obturator fossa. The obturator nerve is preserved. A drain is left in the lower angle of the wound for 24 hours. Mackintosh Marshall says he regards the dissection as complete when he can run an aneurysm needle beneath the iliac vessels throughout their length.

Results of this procedure are as yet too scanty for a decision to be reached as to its efficacy, but on theoretical grounds it would appear to offer hope in a type of case that hitherto had such a poor outlook. It is difficult, however, to be sure that the primary lesion has been controlled by radiation. If extended trial of supervoltage $\mathrm{X}$-radiation proves that cancer can be destroyed in lymph nodes, then the need for the above procedure would disappear.

\section{Ultra Radical Surgery}

Brunschwig, of New York, has evolved the operation of partial or complete pelvic exenteration for uncontrolled cancer of the cervix. Two types of operation are possible: (I) In which radical hysterectomy with lymph node dissection is extended to include the removal of the bladder, vagina and vulva combined with colic implantation of the ureter, and (2) in which all pelvic viscera are excised, including vagina, uterus, adnexae, bladder, lower ureters and pelvic colon combined with implantation of the divided ureters into the sigmoid colon, which is brought out on the surface as an end-colostomy. The rationale of such operations is that autopsy on patients dying of cervical cancer often reveals that the growth has not spread beyond the pelvis. Such operations can be applied to cases where bladder or rectal fistulae are present or where radiation has failed.

A number of patients with advanced pelvic growth are otherwise in fair shape and although this type of operation carries a high risk it gives a chance to patients otherwise doomed. Before embarking on such an operation, it is essential to establish as far as possible that distant metastases are absent, that the kidneys are in good order, and to restore the erythrocyte count, haemoglobin content, plasma protein level and electrolytic balance to normal. It is imperative to combat any urinary infection and to sterilize the bowel as far as possible by pre-operative administration of sulphasuxidine and sulphathalidine. The opera- tion may be carried out in separate abdominal and vaginal stages or by a combined synchrongus technique.

Brunschwig (195I) reported in I95I that out of 29 patients subjected to partial exenteration, including removal of bladder and uretero-çlic transplantation, 6 were well from several mons to 29 months after surgery. Complete pe exenteration, including removal of the colon, fas done for 53 patients with invasion of both bladifer and rectum, 9 of these were well $r_{3}$ to 32 morghs afterwards; 23 per cent. of the patients undergoing exenteration died within 30 days. The operation is also suitable for certain cases wegth extensive radium necrosis, including fistula formation. The place of this massive operation will only be decided with the passage of years. Bonfley (1949), while admiring Brunschwig's work, sobss: 'There comes a point variable according to the particular surgeon's mental make-up when the great risk of an operation coupled with the slight chance of permanent cure or even a year or two of comfortable life, bulks so large that recoils from the likelihood of having to play the part of an executioner.'

At a recent follow-up clinic the author review⿳亠口冋. 50 cases of cervical carcinoma treated by madiotherapy and found only two suitable forosurch surgery on technical grounds, both were we ffover 70 years of age and too frail.

While the problem of wet end-colostomy 丞ft after complete pelvic exenteration has been faffly satisfactorily solved by the Rutzen bag hermetic|lly sealed to the skin round the colostomy, this operation with its necessarily high initial mortafity and doubtful curative value must have a very small field. The operation of partial exentation, however, is a big advance. From timeto time one meets a growth in a comparatively thin woman which has involved the bladder while there is little demonstrable spread in other dipections. Such a case, if treated by thoroßgh irradiation, would almost surely develop a vesical fistula if this is not present already. The operation of partial exenteration in the above circumstances is comparatively easy; in many ways eager than the ordinary extended Wertheim proced for early ligature of the internal iliac vessels and division of the ureters renders the subsequent dissection of the pelvis, including the bladder vagina, relatively simple.

After transplanting the ureters into the cedon and closing the abdomen, the pelvic viscera ofre removed from below. Better still, a second team may carry out the perineal phase while the fipst operator completes the abdominal phase. In very favourable cases, where the growth only involges the upper part of the vagina and bladder, The 
whole operation can be completed from above, the urethra being divided just above the orifice and the vagina at the same level. Oozing from the cut ends is controlled by sutures inserted with a boomerang needle.

\section{Palliative Treatment}

A great deal can be done to render comfortable the last days of a patient who is beyond cure, and it must be remembered that many patients with advanced disease live for a long time. The biggest sources of misery are pain and fistulae. Palliative uretero-colic transplantation for vesical fistula should be employed more often. Where a rectovaginal fistula is present and the bladder intact, a divided loop colostomy makes life far more bearable.

Pain in the terminal stages of cervical cancer is often present both day and night and is due to sensory nerves becoming involved in the growth. Relief may be given in several ways. The commonest employed is the administration of morphia. The disadvantages of this are the constant need to increase the dose, nausea and vomiting in some patients, and the excitement produced in others. The operation of pelvic sympathectomy gives relief when the pain is visceral in origin, but not when it is somatic.

For intre ctable pain of sciatic nature intraspinal injection of absolute alcohol should be tried. This is a simple procedure done with the patient placed on the side opposite to that where the pain is worse. Her pelvis is elevated and her body flexed with the head slightly lowered. In this position the sensory nerve roots lie horizontally and the motor nerve roots usually lie outside the field. In any case, they are less sensitive to the effects of alcohol than the sensory nerve roots. The fourth lumbar interspace is identified and an ordinary lumbar puncture needle inserted. When the needle is in the subarachnoid space $0.75 \mathrm{cc}$. of absolute or 85 per cent. alcohol is injected very slowly, taking two minutes. No C.S.F. is withdrawn into the syringe. Patients are kept on their side for at least an hour after the injection. The patient complains of numbness in the leg or that it feels hot and that she cannot move her leg. If there is pain on both sides, the injection may be repeated a week later with the patient lying on the opposite side. There is a possibility that the alcohol may injure the spinal cord, but if the injection is confined to hopeless cases this is of small moment if pain is relieved.

Greenhill (1947) claims complete relief in 60 per cent. and partial relief in 1o per cent. Maeve Kenny (1947) advocates caudal anaesthesia, using $40-60 \mathrm{ml}$. of proctocaine. When these measures fail and pain is unbearable, it is justifiable to refer the case to a neuro-surgeon with a view to division of the spinothalamic tract.

\section{Leucotomy and Chordotomy}

Wylie McKissock in a personal communication says that when the pain is widely disseminated and the expectation of life is short, leucotomy may be regarded as the best treatment. The patients by then are usually under considerable doses of morphia, which may be withdrawn. The patient when asked if she has pain, replies 'Yes' but she no longer complains of pain. When the expectation of life is longer and the pain localized to one side, chordotomy is better.

\section{Summary and Conclusions}

Gynaecologists all over the world are reconsidering their approach to the problem. Advances have been made and more will follow. The aim must be to allow each patient to receive the treatment most likely to effect a cure and complacency with a five-year survival rate must go.

The Radium Commission have done much to ensure that radiotherapy is adequately carried out and to prevent haphazard employment of radium in ill-equipped institutions. Now that it is clear that surgery still has a place in the treatment, the operations must only be done by trained teams in hospitals with full facilities for pre-operative investigation and post-operative resuscitation.

Radiotherapy remains the standard treatment but should be carried out under the combined direction of gynaecologist and radiotherapist. The man who treats malignant disease in many parts of the body by irradiation and by no other method, is not the man who should have sole responsibility for the treatment of cases of carcinoma of the cervix. The gynaecologist should operate when surgery offers the best chance but not allow his enthusiasm for surgery to persuade him to operate when radiation would be better.

After careful consideration of results and discussion with many authorities, the following scheme for treatment is put forward. Good risk cases with early growths should have radical surgery. The remainder should have radiotherapy, to which may be added extraperitoneal lymph node dissection when the pelvis is large and the local growth apparently controlled. Growths involving the bladder but otherwise free should have partial pelvic exenteration. The position of complete pelvic exenteration remains undecided and will, of course, be a limited one. Gynaecologists who have recently visited the United States and seen patients who had survived after this operation, found they looked well and were contented with their existence.

Several surgeons in England are performing 
complete exenteration when radiotherapy has failed. When their results are collected after a lapse of years, the correct place of the operation may be determined.

More use should be made of pain-relieving operations for advanced cases.

\section{Acknowledgments}

The author's thanks are due to Miss Margar Tod and Dr. Jackson Richmond for their advie on radiotherapy, and to Professor T. Crawford for preparation of the pathological material an micro-photographs.

\section{REFERENCES}

'Annual Report (195I) on the Results of Radiotherapy in Cancer of the Uterine Cervix.' Geneva: World Health Organization. British Empire Cancer Campaign. Philadelphia: Donner Foundation. Stockholm: the Cancerföreningen.

AYRE, J. E. (1949), Trans. 12th Brit. Congr. Obstet. Gynaec. BAUD, JULIET (1948), F. Amer. med. Ass., 138, $1138-1142$. BONNEY, V. (1949), Trans. 12th Brit. Congr. Obstet. Gynaec. BONNEY, V. (1941), Brit. F. Obstet. Gynaec., 48, 421.

BRUNSCHWIG, A. (195I), Amer. F. Obstet. Gynec., 6r, 1193.

BRUNSCHWIG, A. (1951), Amer. F. Roentgen., 65, 720.

CANTRIL, S. T. (1950), 'Radiation Therapy in the Management of Cancer of the Uterine Cervix,' Charles C. Thomas, Springfields, Ill., U.S.A., p. 179.

GLUCKSMAN, A., and SPEAR, F. G. (1945), Brit. f. Radiol., 18, 313.

GLUCKSMAN, A. (1949), Trans. 12th Brit. Congr. Obstet. Gynaec. GREENHILL, J. P. (1947), Brit. med. F., i1, 859.

HARNETT, W. L. (1949), Brit. F. Cancer, $111,433$.

HEYMAN, J. (1947), f. Amer. med. Ass., 135, 412.

HEYMAN, J. (1949), Trans. 12th Brit. Congr. Obstet. Gynaec.

HINSELMANN, H. (1933), Zeitsch. Geb. Gynaek., C.r, 142.

HOWKINS, J. (1951), Lancet, ii, 872. HOWSON, J. Y., and MONTGOMERY, J. (1949), Amer.

KENNEY, MAEVE (1947), Brit. med. F., ii, 862.

LACASSAGNE, A., et al. (1941), 'Radiotherapie des Cancer du Col. d'Utero,' Paris, Masson et Cie.

MEIGS, J. V. (1951), Amer. F. Roentgen., 65, 698. NOVAK, E. (1947), 'Gynaecological and Obstetrical Patholog疋,
Philadelphia, W. B. Saunders, p. 98.

PAPANICOLAOU, G. N. (1928), Proc. 3rd Race Bettermem Conference, p. 538.

SCHLINK, H. H. (1950), F. Obstet. Gynaec., 57, 714.

STRACHAN, G. I. (1949), Trans, i2th Brit. Congr. Obstet. Gyma

TAUSSIG, F. J. (1943), Amer. F. Obstet. Gynec., 45, 733.

TELINDE, R. W., and GALVIN, G. (1944), Amer. F. Obste? Gynec., 48, 774 .

THOREN, S. (1945), Acta Radiol., 26, 249.

TOD, MARGARET C. (1947), Ibid., 28, 564 .

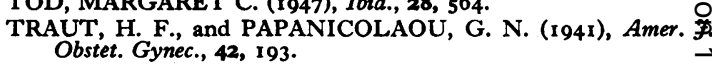

WARNER, S., MEIGS, J. V., JAFFE, H. L., and SEVERANCF A. (1939), Surg. Gynec. Obstet., 69, 645.

WERTHEIM, A. (1950), Brit. med. F., ii, 689.

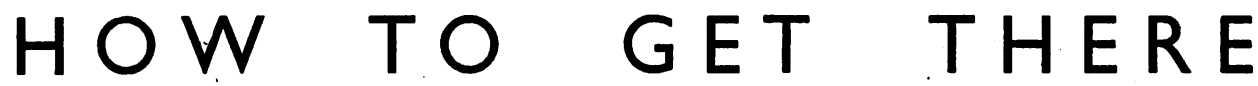

An Address Book for the Medical profession, showing how to reach the various Colloges, Societies, Institutes and Hospitals in and near London. Third edition: 1950.

Published by the

FELLOWSHIP OF POSTGRADUATE MEDICINE

60 Portland Place, London, W. I

Price 2s. 6d.

\section{RUTHIN CASTLE, NORTH WALES}

A Clinic for the diagnosis and treatment of Internal Diseases (except Mental or Infectious Diseases). The Clinic is provided with a staff of doctors, technicians and nurses.

The surroundings are bea utiful. The climate is mild. There is central heating throughout. The annual rainfall is 30.5 inches, that is, less than the average for England.

The Fees are inclusive and vary according to the room occupied.

For particulars apply to THE SECRETARY, Ruthin Castle, North Wales. 